\title{
Determination of Archie's Tortuosity Factor from Stoneley Waves in Carbonate Reservoirs
}

\author{
Keyvan Khayer \\ Shahrood University of \\ Technology \\ Shahrood, Iran
}

\author{
Adel Shirazy \\ Amirkabir University of \\ Technology \\ Tehran, Iran
}

\author{
Abdolhamid Ansari \\ Yazd University \\ Yazd, Iran
}

\author{
Hamed Nazerian \\ University of Catania \\ Catania, Italy
}

\author{
Aref Shirazi \\ Amirkabir University of \\ Technology \\ Tehran, Iran
}

\author{
Ardeshir Hezarkhani \\ Amirkabir University of \\ Technology \\ Tehran, Iran
}

\begin{abstract}
One of the fundamental equations in calculate the saturation of fluid in hydrocarbon reservoirs is the Archie's equation. In addition to the parameters measured by well logging such as porosity and resistivity, there are others parameters that called Archie's coefficients. Archie provides constant values for this coefficient base on experimental core's data, accordance with saturation formula in sandstone. In carbonate reservoirs nevertheless the sandstone reservoirs, high heterogeneity, variety in lithology and texture, shape and distribution of pores, due to this coefficient is not constant. So, variation of tortuosity as a coefficient that depends on the way correlation between pores, is high and considering a constant value due to error in calculation of fluid saturation. In this study, with the stoneley waves measured from DSI tools and required calculation, the value of tortuosity coefficient calculated continuously in well no.10 Darkhovin field. The regression of calculated values with the core data is 83.16 percent, that showed this method is useable for calculation the tortuosity.
\end{abstract}

Keywords: Archie's equation, tortuosity, DSI tool, Stoneley waves.

\section{INTRODUCTION}

Geological surveys, which include geophysical and geochemical methods and remote sensing, are widely used [113]. One of these applications is using in carbonate reservoirs. One of the most important parameters in reservoir, is fluid saturation [14-17] which can be studied by geophysical methods and well-logging [18, 19]. Several formulas are given for saturation calculation. The fundamental equation provides by Archi. In his formula, addition the parameters that measured from well logging such as the resistivity and porosity, there are three parameters called Archie's coefficient (equation1)

$\mathrm{F}=\frac{a}{\emptyset^{m}}$

where $\mathrm{F}$ is formation factor, $\mathrm{m}$ is cementation coefficient, $a$ is tortuosity coefficient and $\emptyset$ is porosity.

Archie provided constant values for this coefficient base on core analysis and correlating them with saturation formula defined for sandstone. In carbonate rocks, unlike sandstone rocks, the high degree of heterogeneity, variety of lithology and texture, pores shape and their distribution due to have large variety. So variation of tortuosity coefficient, which depends on the way of pores connection and form of relevant conduits, is high and considering a constant value of this parameter as done in sandstone reservoirs cause large error in fluid saturation calculation. There are direct and indirect methods for determining this coefficient. Direct method and in direct method such as core's experimental and NMR logging respectively. Another method is using the DSI logging. With this method can determining tortuosity and permeability by less cost and time. An acoustic waveforms contain valuable information. With used the Stoneley wave can provide relation for calculating the permeability and tortuosity.

Quantitative modeling by resonbeaum(1974),Schmitt and Bouchon(1984) [20], and by Schmitt et al.(1988)[21] supports the conclusion that attenuation increases with permeability and with pore fluid mobility; i.e., attenuation decrease as pore fluid viscosity increase. Resonbaum based his finding on synthetic acoustic signals covering a wide range of frequencies. Hornbyetai. (1989), Tang and Cheng (1988) [22], and Giiler and Toksoz (1987) [23] have studied the propagation of Stoneley wave across borehole fractures. Beri and et.al (2000) [24] proposed equation that by using it, can calculated the Stoneley slowness in nonpermeable zone. Aladani and Barati (2003) [25], studied the effect of permeability on Stoneley slowness. They presented Stoneley slowness in around the borehole is divided in to stoneley slowness in nonpermeable and permeable zones. Hadavand and Moradzadeh (2007) [26] used Al-adany's method in sandstone reservoir. They showed this method in carbonate and sandstone reservoirs is useable. Mosalman Nejad (2008) compared the permeability that obtained from Stoneley waves, with permeability from NMR logging and showed that the result of Stoneley waves is more similarities with cores analysis. Sun and et al. in 2012 studied the full spectrum of sonic waves and examining permeability associated with each type of sonic waves. They found that changed in the speed and extent of slowness in Stoneley wave is more appropriate with permeability. Guan and et al. (2013) [27] investigated 
Stoneley waves in pore water saturated and obtained a continuous log that showed the permeability changes in around of the borehole.

In this study by using Stoneley slowness and shear waves from DSI tools, the tortuosity has calculated as a continuous $\log$ around the borehole [25].

It is worth mentioning that in addition to all studies on mineral and organic resources, in any study can be discussed the beauties of the area and the discussion of geotourism [28].

\section{METHODOLOGY}

At low frequency the Stonely mode become the tube wave and propagates as a piston-like compression of the borehole. When the borehole crosses permeable zones or permeable fractures, some fluid movement occurs between the borehole and the formation. this results in some energy loss, hence attenuation and a slowing down of the wave, hence increased Stoneley wave slowness (Brie 2000) [24]. The elastic slowness of a Stoneley wave at low frequencies in an elastic formation (non-permeability) is calculated using the expression in equation 2 :

$\Delta t_{s t-e l}^{2}=\frac{\rho_{m}}{\rho_{b}}\left(\Delta t_{s h}\right)^{2}+\Delta t_{b f}^{2}$

(2)

$\Delta t_{s t-e l}$ is the slowness in nonpermeable zone

$\rho_{b}$ is the bulk density of the rock

$\Delta t_{b f}$ is the borehole fluid(mud)slowness.

$\rho_{m}$ is the density mud

$\Delta t_{s h}$ is the shear slowness of the rock

The difference between $\Delta t_{s t-e l}$ and $\Delta t_{s t}$ indicates a fluid mobility indicator.

By cross plotting $\Delta t_{s t-e l}$ versus $\frac{\Delta t_{s h}}{\rho_{b}}$ across non permeable zones, the slope of the straight line is $\rho_{m}$ and y-intercept is $\Delta t_{b f}^{2}$. There is one condition on such linear fit, that all data on cross plot should be above or on the fit line. With determining $\Delta t_{b f}^{2}$, can calculate the $\Delta t_{s t-e l}$ around the borehole, according to the equation 3 .

$\Delta \mathrm{t}_{\mathrm{st}}=\Delta \mathrm{t}_{\mathrm{st}-\mathrm{el}}+\Delta \mathrm{t}_{\mathrm{p}}$

The ratio of $\frac{\Delta \mathrm{t}_{s t-e l}}{\Delta \mathrm{t}_{s t}}$ represent the way pores media that called permeability index. Permeability index is not permeability estimation, but it is an index of fluid movement in porous media around the borehole. Since fluid movement is a function of pore throat distribution, pore shape and pore size, the Stoneley permeability index is a tortuosity index only.

\section{DATA ACQUISTION}

In this study target is determination the tortuosity factor by Stoneley waves in one of the carbonate reservoirs in Southern Iran. This reservoir is located at the oil field with limestone lithology that belongs of construction to the flat plateau Arabic. Fahlian formation is the reservoir rock of this field that has about 500 meters carbonate deposit. In this present study well, Resistivity, SGR, NPHI and Sonic logs were acquired. That showed in figure 1. Clay type cannot be identified accurately due to very low concentration of clay in the zone of study. Illite was assumed as main clay in this formation.

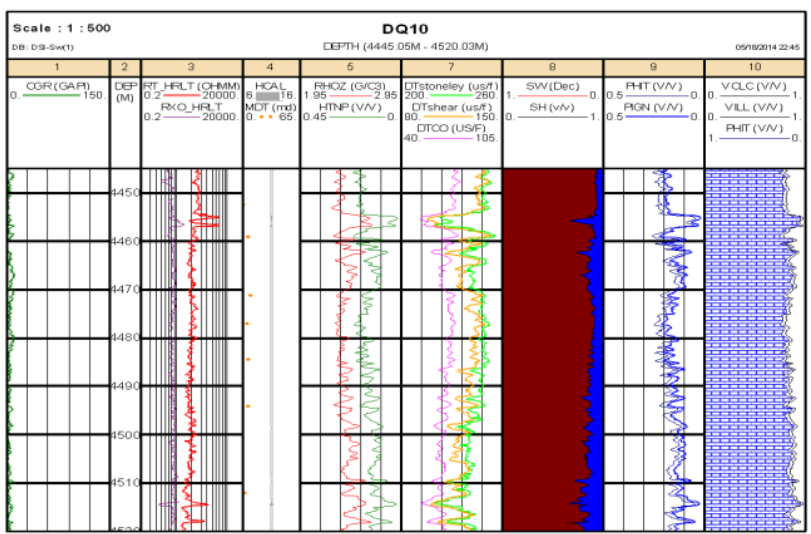

Figure1. Petrophysical logs in well study

\section{RESULTS AND DISCUSSION}

Using the Stoneley wave that measured by DSI tool for calculate the tortuosity factor in this well according above Descriptions.

First with petrophysical logs determined the non-permeable zone. A cutoff 5\% was applied to total porosity. Only those zones were taken in to consideration to predict a nonpermeable zone that had total porosity less than $5 \%$. The zone that considers as non-permeable zone, locate at $3330 \mathrm{~m}$ to $3360 \mathrm{~m}$. In this zone the total porosity is less than $5 \%$ and the main lithology is limestone. Cross plotting $\Delta t_{s t-e l}^{2}$ versus $\frac{\Delta t_{s h}}{\rho_{b}}$ in this zone, showed in figure 2. The slope of straight line is 2.9 that represent the $\rho_{m}$ and 39000 is refer to $\Delta t_{b f}^{2}$.

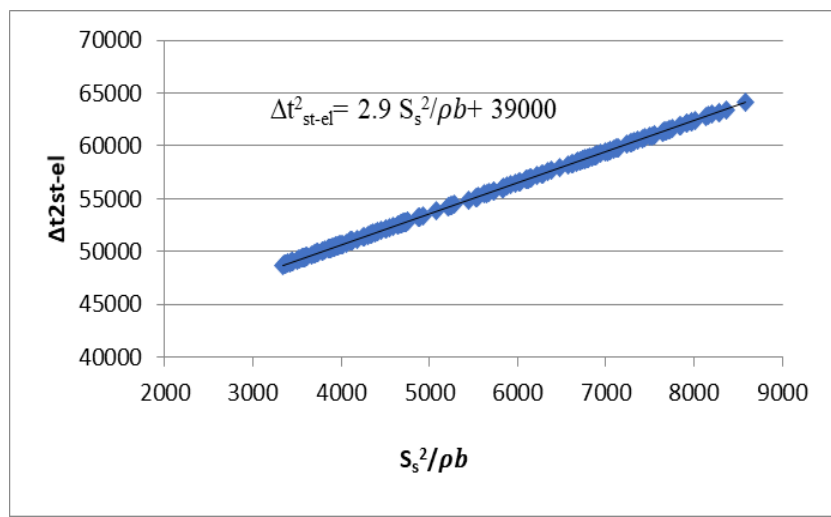

Figure2. Cross plot $\Delta t_{s t-e l}^{2}$ versus $\frac{\Delta t_{s h}}{\rho_{b}}$

Now with obtained $\Delta \mathrm{t}_{\mathrm{bf}}^{2}$, can calculating the $\Delta \mathrm{t}_{\mathrm{st}-\mathrm{el}}$ for around the borehole. Then with constitute ratio $\frac{\Delta \mathrm{t}_{\mathrm{st}-\mathrm{el}}^{2}}{\Delta \mathrm{t}_{\mathrm{st}}}$, determining the permeability index that can consider as tortuosity factor. In figure 3 and table 1 showed the $\log$ of variation of tortuosity continuously and the point that shown on log is tortuosity calculated from core's experimental. 
Table1. Comparison between calculated tortuosity and core's tortuosity

\begin{tabular}{|c|c|}
\hline Core's $^{\prime}$ tortuosity & Calculated tortuosity \\
\hline $\mathbf{0 . 9 8 8 7 9}$ & 0.993344 \\
\hline $\mathbf{0 . 9 7 5 4 6}$ & 0.976247 \\
\hline $\mathbf{0 . 9 8 2 3}$ & 0.985364 \\
\hline $\mathbf{0 . 9 8 0 1 1}$ & 0.973307 \\
\hline $\mathbf{1}$ & 1.001924 \\
\hline $\mathbf{1}$ & 1.005411 \\
\hline
\end{tabular}

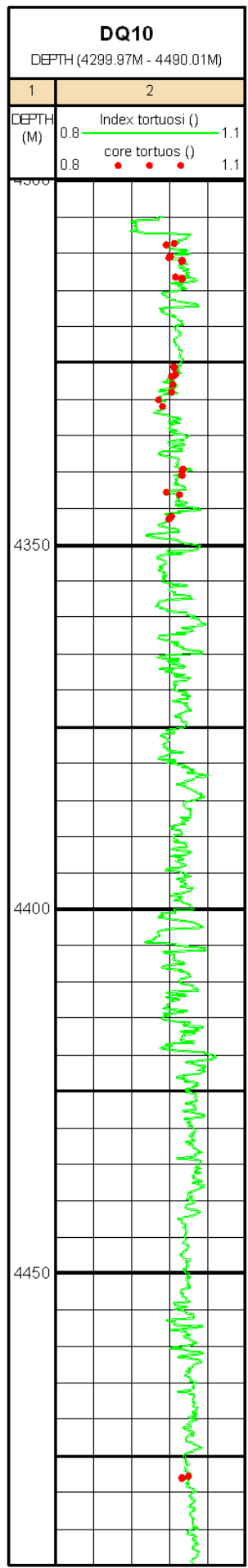

Figure3. Variation of tortuosity continuously and the point that shown upon the log is tortuosity calculated from core's analysis
The regression of calculated values with the core data is 83.16 percent (figure 4), that showed this method is useable for calculation the tortuosity.

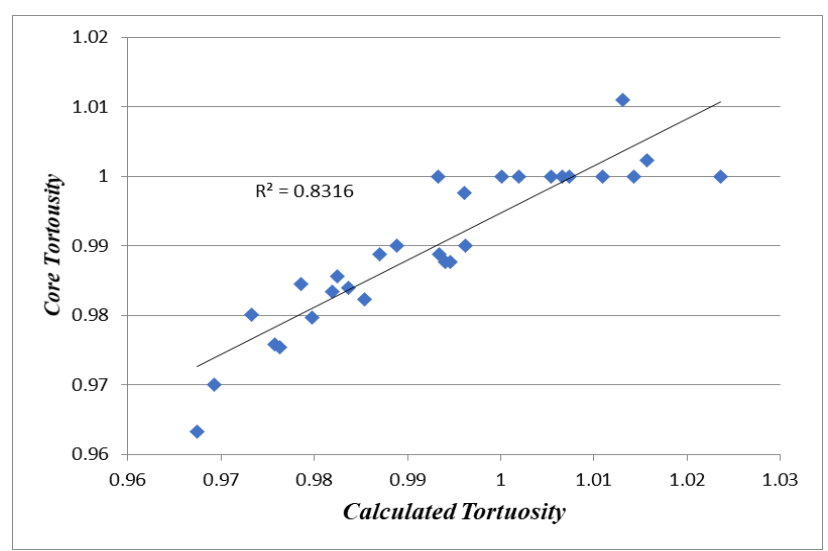

Figure4. comparison between calculated tortuosity and tortuosity from core's experimental.

\section{CONCLUSIONS}

High heterogeneity, variety in lithology and texture, shape and distribution of pores, in carbonate reservoirs due to tortuosity not constant and has variation. The method that usually used for determined this coefficient is core's experimental. This method is very time consuming and not economically and could not give a continuous log. In this study using the Stoneley wave that measured by DSI tool to calculate the tortuosity coefficient as a continuous log. Results represent to good performance of this method. The regression of calculated values with the core data is 83.16 percent, so this method is useable for calculation the tortuosity. With continuous tortuosity log can calculate water saturation with higher accuracy when use Archie's low.

\section{REFERENCES}

[1] Adel, S., Z. Mansour, and H. Ardeshir, Geochemical behavior investigation based on $k$ means and artificial neural network prediction for titanium and zinc, Kivi region, Iran. Известия Томского политехнического университета. Инжиниринг георесурсов, 2021. 332(3): p. 113125.

[2] Alahgholi, S., A. Shirazy, and A. Shirazi, Geostatistical studies and anomalous elements detection, Bardaskan Area, Iran. Open Journal of Geology, 2018. 8(7): p. 697-710.

[3] Shirazi, A., et al., Remote sensing studies for mapping of iron oxide regions, South of Kerman Iran. International Journal of Science and Engineering Applications, 2018. 7(4): p. 45-51.

[4] Shirazi, A., et al., Exploration Geochemistry DataApplication for $\mathrm{Cu}$ Anomaly Separation Based On Classical and Modern Statistical Methods in South Khorasan, Iran. International Journal of Science and Engineering Applications, 2018. 7: p. 39-44.

[5] Shirazi, A., A. Shirazy, and J. Karami, Remote sensing to identify copper alterations and promising regions, Sarbishe, South Khorasan, Iran. International Journal of Geology and Earth Sciences, 2018. 4(2): p. 36-52. 
Shirazi, A., et al., Geostatistics studies and geochemical modeling based on core data, sheytoor iron deposit, Iran. Journal of Geological Resource and Engineering, 2018. 6: p. 124-133.

[7] Shirazy, A., et al., Application of Remote Sensing in Earth Sciences-A Review.

[8] Shirazy, A., et al., Geochemical and geostatistical studies for estimating gold grade in tarq prospect area by k-means clustering method. Open Journal of Geology, 2019. 9(6): p. 306-326.

[9] Shirazy, A., et al., Exploratory Remote Sensing Studies to Determine the Mineralization Zones around the Zarshuran Gold Mine. International Journal of Science and Engineering Applications, 2018. 7(9): p. 274-279.

[10] Shirazy, A., et al., Geophysical study: Estimation of deposit depth using gravimetric data and Euler method (Jalalabad iron mine, kerman province of IRAN). Open Journal of Geology, 2021.

[11] Shirazy, A., M. Ziaii, and A. Hezarkhani, Geochemical Behavior Investigation Based on $K$ means and Artificial Neural Network Prediction for Copper, in Kivi region, Ardabil province, IRAN. Iranian Journal of Mining Engineering, 2020. 14(45): p. 96-112.

[12] Shirazy, A., et al., Geostatistical and remote sensing studies to identify high metallogenic potential regions in the Kivi area of Iran. Minerals, 2020. 10(10): p. 869.

[13] Hearst, J.R. and P.H. Nelson, Well logging for physical properties. 1985.

[14] Doodran, R.J., et al., Minimalization of Ash from Iranian Gilsonite by Froth Flotation. Journal of Minerals and Materials Characterization and Engineering, 2020. 9(1): p. 1-13.

[15] Khakmardan, S., et al., Evaluation of Chromite Recovery from Shaking Table Tailings by Magnetic Separation Method. Open Journal of Geology, 2020. 10(12): p. 1153-1163.

[16] Khakmardan, S., et al., Copper oxide ore leaching ability and cementation behavior, mesgaran deposit in Iran. Open Journal of Geology, 2018. 8(09): p. 841.

[17] Shirazi, A., et al., Introducing a software for innovative neuro-fuzzy clustering method named NFCMR. Global Journal of Computer Sciences: theory and research, 2018. 8(2): p. 62-69.

[18] Galiuk, H.S., K. Saadat, and E. Kazemzadeh. A case study of saturation exponent measurement on some carbonate cores at full reservoir conditions. in International Symposium of the Society of Core Analysts held in Austin, Texas, USA. 2011.

[19] Darling, T., Well logging and formation evaluation. 2005: Elsevier.

[20] Schmitt, D. and M. Bouchon, Full wave synthetic acoustic logs in saturated porous media, in SEG Technical Program Expanded Abstracts 1984. 1984, Society of Exploration Geophysicists. p. 1720.

[21] Schmitt, D.P., M. Bouchon, and G. Bonnet, Fullwave synthetic acoustic logs in radially semiinfinite saturated porous media. Geophysics, 1988. 53(6): p. 807-823.

[22] Tang, X. and C.-H. Cheng, Fast inversion of formation permeability from Stoneley wave logs using a simplified Biot-Rosenbaum model. Geophysics, 1996. 61(3): p. 639-645.

[23] Güler, S., et al., The detection of geological fault lines in radar images, in Pattern Recognition Theory and Applications. 1987, Springer. p. 193201.

[24] Brie, A., et al., Quantitative formation permeability evaluation from Stoneley waves. SPE Reservoir Evaluation \& Engineering, 2000. 3(02): p. 109-117.

[25] Al-Adani, N. and A. Barati. New hydraulic unit permeability approach with DSI. in SPWLA 9th formation evaluation symposium, Japan. 2003.

[26] Khayyer, K., A. Moradzadeh, and B. Tokhmchi, A New Approach to Estimate Cementation Exponent in Carbonate Reservoirs. Journal of Analytical and Numerical Methods in Mining Engineering, 2020. 9(21): p. 1-7.

[27] Guan, W., H. Hu, and Z. Wang, Permeability inversion from low-frequency seismoelectric logs in fluid-saturated porous formations. Geophysical Prospecting, 2013. 61(1): p. 120-133.

[28] Shirazi, A. and A. Shirazy, Introducing Geotourism Attractions in Toroud Village, Semnan Province, Iran. International Journal of Science and Engineering Applications, 2020. 9(6): p. 79-86. 